\title{
La delimitación de los espacios de ocio en Pompeya
}

\author{
The delimitation of the recreational spaces in Pompeii
}

\author{
NoEmi Raposo GutiÉRREZ \\ Universidad de Huelva
}

Recibido: 19/12/2017

Revisado: 28/05/2018
Aceptado: 31/05/2018

Publicado: 29/06/2018

\section{RESUMEN}

Este estudio se centra en conocer la delimitación de los espacios de ocio en la ciudad romana de Pompeya. Esta ciudad romana nos brinda la posibilidad de realizar un estudio de tal índole, ya que es considerada una cápsula del tiempo y podemos ver en ella el ejemplo más claro de cómo se organizaba urbanísticamente una ciudad romana en el siglo I d.C.

Los espacios de ocio como los teatros, anfiteatros o palestras, que encontramos en las ciudades romanas son considerados res publicae in publico uso o res universitatis, por tanto el estudio de la legislación ha sido clave para analizar la delimitación de estos espacios y sus posibles invasiones. A través de los textos legislativos hemos averiguado cuál era la norma que debía seguir una ciudad romana en la delimitación de sus espacios de ocio y hemos comprobado si la ciudad de Pompeya cumplía con rigor esta normativa urbanística.

Para analizar la delimitación de todos estos espacios se ha llevado a cabo un estudio de los bloques irregulares de piedra (termini) que los delimitan. Estos termini estaban fuertemente protegidos por la legislación. Por ello, a todo aquel que osara mover o sobrepasar dichos termini se le impondría una sanción por parte de la ciudad e incluso en algunos casos por parte del emperador.

Palabras Clave

Delimitación; Pompeya; Espacios de ocio; Terminus; Invasión.
ABSTRACT

This study focused on knowing the delimitation of the recreational spaces in the roman city of Pompeii. This city makes such study possible because it is well conserved and we can regard it as the clearest example of how a roman city was organized in the 1st century AD.

The recreational spacesastheaters, amphitheaters or gymnasiums, in roman cities, were considered res publicae in publico uso or res universitatis. Therefore, the study of legislation has been a key to analyze how the limits of these spaces were marked and how they could be occasionally invaded. Through the study of legislative texts, we have found the norms that should have been followed to delimit the recreational space of an ancient roman city, and we have verified whether people in Pompeii abided by these laws.

Moreover, boundary stones, called termini, were examined to analyze the delimitation of the public spaces. These stones were carefully protected by the urban laws. Therefore, anyone who dared to move or exceed these terms would be imposed a sanction by the city government and even in some cases by the emperor.

\section{KEY WORDS}

Delimitation; Pompeii; Recreational spaces; terminus; Invasion. 


\section{INTRODUCCIÓN}

Los espacios de ocio en una ciudad romana suelen ser diversos, contamos con los teatros, los anfiteatros, las palestras y las termas. En este estudio nos vamos a centrar en los edificios de espectáculos como son los teatros y anfiteatros, además de los edificios de ocio dedicados al deporte como las palestras en la ciudad romana de Pompeya (Figura 1).

Esta ciudad romana nos brinda la posibilidad de realizar un estudio de tal índole, ya que es considerada una cápsula del tiempo después de haber sido sepultada debido a la erupción del Vesubio en el año 79 d.C. Por tanto, Pompeya conserva todos los edificios de ocio con los que contaba una ciudad romana sin modificaciones posteriores al siglo I d.C.

\section{LA DELIMITACIÓN DE LOS ESPACIOS DE OCIO EN LA LE-} GISLACIÓN

Los espacios de ocio son considerados res publicae in publico uso y forman parte de las cosas de derecho humano (res humani iuris), es decir, son lugares que no se consideran propiedad privada, sino que tienen un uso público. Estos espacios eran calificados como res universitatis, porque eran cosas universales que pertenecían a la comunidad colonial o al municipio (De Marco, 2004, 19-20 y Lovato et alii. 2014, 251-252). Normalmente, no eran edificios construidos por la ciudad, sino que solían construirse por los magistrados o ciudadanos con cierto nivel económico, cuyo fin era ser reconocidos por los ciudadanos como los donadores a la ciudad de un edificio de ocio y con ello poder conseguir votos a la hora de presentarse a cualquier cargo político. Sin embargo, estos edificios no pertenecían a los privados, sino que pertenecían a la ciudad cómo podemos ver recogido en la legislación romana, ya que eran res publicae (De Marco, 2004, 18-19): "Son de la comunidad, y no de los particulares, por ejemplo, los teatros que hay en las ciudades, y los estadios, y otras cosas semejantes, así como también algunas otras cosas que son comunes a los de las ciudades" (Dig. ${ }^{1}$ 1, 6, 6.1; Inst. $2,1,6)^{2}$.

1 Corpus Iuris Civilis o Digesto es una recopilación de la jurisprudencia romana realizada por el emperador Justiniano (533 d.C.), que abarca desde el emperador Adriano hasta su época.

2 Inst. 2, 1, 6. Universitatis sunt, on singulorum, veluti quae in covitatibus sunt, ut theatra, stadia, et similia, et si qua alia sunt communia civitatum.
Sin embargo, resulta difícil encontrar información sobre la normativa que regulase la implantación y delimitación de estos edificios dentro de una ciudad romana, como podemos ver que si existe de otros edificios o espacios públicos o de uso público, como las aceras, las fuentes públicas, las torres de agua, las puertas, etc. (Raposo, 2015). Posiblemente, la normativa que regulaba la construcción de edificios de espectáculos en época romana se recogería en las leyes municipales de cada ciudad, y probablemente serían diferentes unas de otras. Para poder hallar más datos hemos realizado un análisis de las inscripciones encontradas tanto en teatros de la Campania, concretamente en Herculano y en el teatro de Pompeyo en Roma; además de estudiar anfiteatros de la Campania como los situados en la ciudad de Capua, Nola, Pozuoli, así como en Roma, ya que el Coliseo cuenta con un gran número de inscripciones analizadas por Silvia Orlandi (Orlandi, 2004). No obstante, no hemos hallado inscripciones que nos aporten referencia con respecto a la delimitación e instauración de estos edificios. Solamente encontramos inscripciones relacionadas con la fecha en la que se construyen, quienes fueron sus constructores o los benefactores, es decir, las personas que ayudaron a pagar el edificio, las restauraciones que en ellos se realizaban e incluso quienes eran los propietarios de los asientos dentro de los teatros o anfiteatros. Por ello, llegamos a la conclusión que estos espacios debieron tener una normativa interna municipal, pero que desafortunadamente no ha llegado a nuestros días.

A pesar de ello, pensamos que estos edificios de espectáculos se delimitaran de la misma forma que el resto de edificios o zonas públicas de las ciudades romanas, y es que se delimitasen a través de los termini. A lo largo de la ciudad de Pompeya, podemos encontrar una serie de termini de roca volcánica negra informes, es decir, que no tienen una forma específica ni un tamaño determinado. Estos mojones están colocados en distintos espacios de la ciudad. Por sus características son muy visibles en cualquier lugar en el que se colocan y diferentes por su forma y color a cualquier material empleado en el entorno. Los podemos localizar delimitando tumbas, edificios públicos, fuentes, plazas, aceras, etc. (Raposo, 2015, 106).

La colocación de los termini era realizada en conjunto entre los agrimensores, que eran los operadores que se encargaban de hacer las mediciones y los gromáticos, que eran los encargados de utili- 


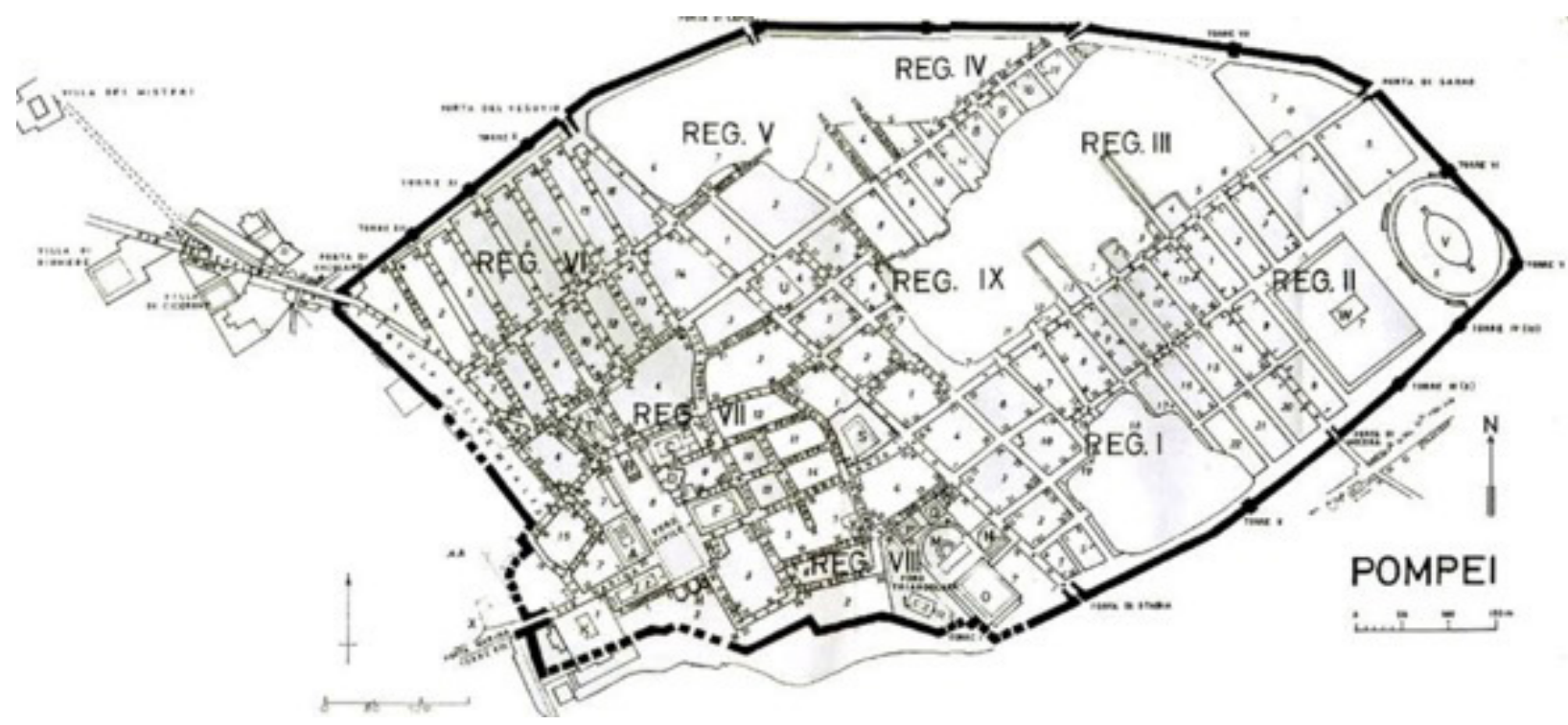

Figura 1. Plano de Pompeya, Eschebach (archaeology.uakron.edu)

zar la groma. Ésta era la herramienta principal que utilizaban los romanos para realizar las mediciones y trazar las líneas sobre el terreno necesarias para la construcción de calles, ciudades, templos, centuriaciones de terrenos agrícolas, etc. Con este sistema posiblemente se iban colocando los mojones para delimitar los lugares públicos y privados tanto dentro como fuera de la ciudad. Los termini seguían un ritual sagrado de colocación, pero no siempre se realizaban estos rituales. El agrimensor Sículo Flaco defiende que era un acto voluntario, porque bajo algunos mojones no hay nada enterrado; pero bajo otros encontramos cenizas, carbones, fragmentos de cerámica o de vidrio, o ases bajo cal o yeso. Este ceremonial nos pone de manifiesto el valor religioso que quería darse a la colocación e inmovilidad de estas piedras, que eran así protegidas no sólo por las leyes municipales, sino por creencias y costumbres tradicionales de índole religiosa (Raposo, $2015,104)$. De este modo los termini adquirían un carácter sagrado, por lo que eran honrados como si se trataran del mismo dios Terminus. Se cuenta que el rey Numa estableció el día 23 de febrero como la fiesta de las Terminalia en honor al dios Terminus, en las cuales se realizaba un ritual muy parecido al que se ejecutaba en la colocación de los termini (Daremberg et alii. 1877-1919, 123-124).

La legislación sobre la colocación, así como sobre los intervalos entre los termini, sería muy variada. Debían colocarse en todos los ángulos y ángulos entrantes, pero después se disponían sin intervalos fijos, y variaban según las regiones $(\mathrm{Hy}-$ ginus et alii. 1998, 81). Existía una legislación sobre las penas que se imponían a aquel que osara mover dichos termini, disposiciones conocidas como Terminus Motus. En estas leyes observamos que no había una multa establecida por el crimen de mover los termini, sino que se debía adecuar la pena según la condición social del transgresor (Dig. 47, 21,1) 3 .

En la ley agraria que dio Julio César se establecía una pena económica contra los que movieran los termini. Por cada uno que sacaran o movieran de sitio, se imponía una multa pública de cincuenta áureos y daba igual la condición social del agresor (Dig. 47, 21, 8. $)^{4}$.

En otra ley agraria dictada por el emperador Nerva se estableció la pena capital para el esclavo o esclava que hubiera modificado la colocación de un terminus sin conocimiento de su dueño, a no

3 Dig. 47, 21, 1. Terminorum avulsorum non mulcta pecuniaria est, sed pro condicione admittentium coercitione transigendum.

4 Dig. 47, 21, 8. Lege agraria, quam Caius Caesar tulit adversus eos, qui terminos statutos extra auum gradum finesve moverint dolo malo, pecuniaria poena constituta est; nam in terminos singulos, quos eiecerint locove moverint, quinquaginta aureos in publicum dari iubet; et eius actionem, petitionem, ei, qui volet, esse iubet. 
ser que el dueño prefiriera pagar la multa. También debían ser castigados, según su condición personal y la gravedad del hecho los que alterasen el aspecto de los límites (Dig. 47, 21, 8, 1) .

Por último, en un rescripto del emperador Adriano se argumentó que debía existir una pena según la condición personal y la intención de él que lo hizo. Con ello se pretendía decir que si los convictos eran personas de una clase social elevada, era evidente que lo habían hecho para apoderarse de confines ajenos: por eso podían ser condenados a destierro temporal, que variaba según la edad del condenado, más larga para un joven y más breve para un condenado de edad avanzada. Pero si lo habían hecho por servir a alguien, debían ser castigados y condenados a trabajos forzados por un bienio, y si hubiesen hurtado los termini por ignorancia o casualmente para utilizar las piedras, bastaría castigarles con azotes (Dig. 47, 21, 2) ${ }^{6}$.

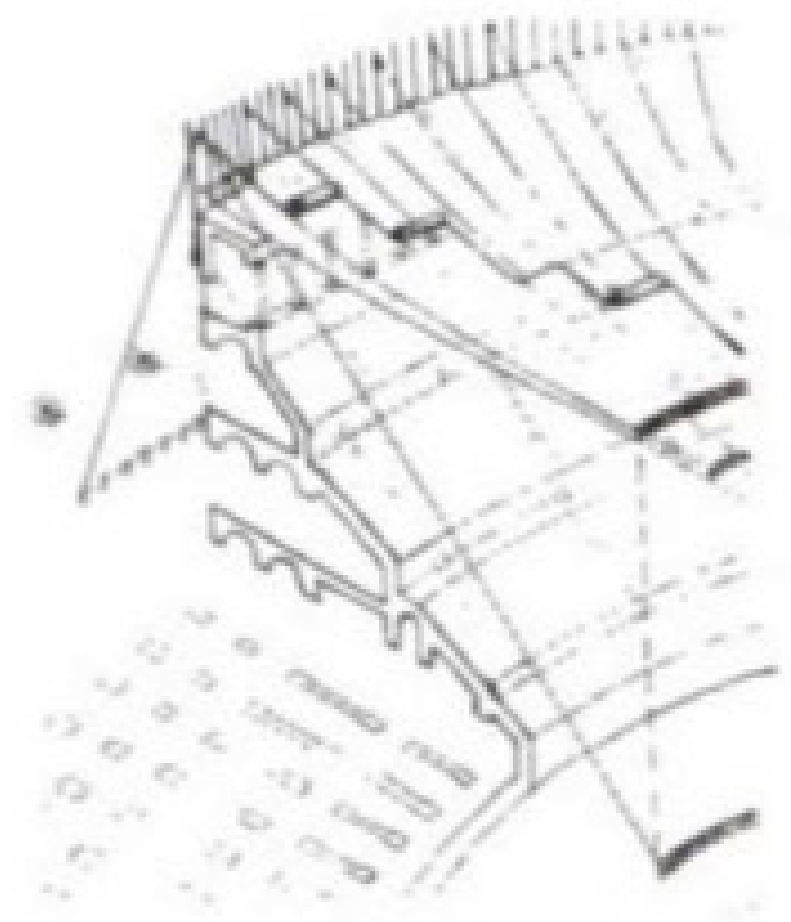

Figura. 2. Reconstrucción velarium del Coliseo. Fuente: Paolucci, 2006, 114.

5 Dig. 47, 21, 8, 1. Alia quoque lege agraria, quam Divus Nerva tulit, cavetur, ut si servus servave insciente domino dolo malo fecerit, ei capital esse, nisi dominus dominave mulctam sufferre maluerit.

6 Dig. 47, 21, 2. Divus Hadrianus in haec verba rescripsit: "Quin pessimun facttum sit eorum, qui terminos finium causa positos propulerunt, dubitari non potest. De poena tamen modus ex condicione personae
Un claro ejemplo de delimitación a través de termini en un edificio de espectáculo lo tenemos en el anfiteatro Flavio de Roma, conocido como Coliseo. Este edificio de espectáculo conserva una serie de termini que lo delimitan en uno de sus lados, al igual que encontramos en el resto de espacios dentro y fuera de una ciudad romana, como las aceras, las fuentes públicas, las torres de agua, los templos, los compita, los acueductos o las tumbas (Raposo, 2015, 106).

Sin embargo, respecto a estos termini existe un debate en relación a su función, ya que tradicionalmente la comunidad científica ha consolidado la idea que la utilidad que tenían estos cinco termini, que se encuentran a 18 metros del Coliseo, y que en su día serían unos 160 rodeando todo el anfiteatro, servían para sujetar las cuerdas del velarium del anfiteatro (Figura 2) (Paolucci, 2006, 114). Por otro lado, se ha pensado que la función de estos termini fuera para frenar el acceso de los vehículos a la plaza pavimentada en travertino que rodeada al anfiteatro, además de servir para controlar el acceso peatonal al Coliseo (Bomgardner, 2000, 5).

Otro ejemplo, lo tenemos en el anfiteatro de $\mathrm{Ca}-$ pua, que al igual que el Coliseo estaba rodeado por una plaza pavimentada y por unos termini, a los que se les ha atribuido la doble función de sujetar las cuerdas del velarium, y de poner sobre ellos unos postes de madera para control de la muchedumbre que entraba al anfiteatro, como ocurría en el Coliseo (Bomgardner, 2000, 90-91).

No obstante, pensamos que no fuesen solo esas sus funciones, sino más bien su uso principal fuera la de delimitar el espacio destinado al edificio y que con ello nadie osara sobrepasar dicho límite y ocupar ese espacio, ya que esos termini formaban una plaza pavimentada alrededor del anfiteatro para disponer de un espacio abierto para facilitar el tránsito a los espectadores. Por lo tanto, defendemos la teoría de que estos termini tuvieran una triple función, por un lado la función principal de delimitación del espacio para evitar abusos de ocu-

et mente facientis magis statui potest; nam si splendidiores personae sunt, quae convincuntur, non dubie occupandorum alienorum finium causa id admiserunt, et possunt in tempus, ut cuiusque patiatur aetas, relegari, id est, si iuvenior, in longuis, si senior, recisius; si vero alii negotium gesserunt, et ministerio functi sunt, castigari, ey ad opus biennio dari; quodsi per ignorantiam aut fortuito lapides furati sunt, sufficiet eos verberibus decidere."). 


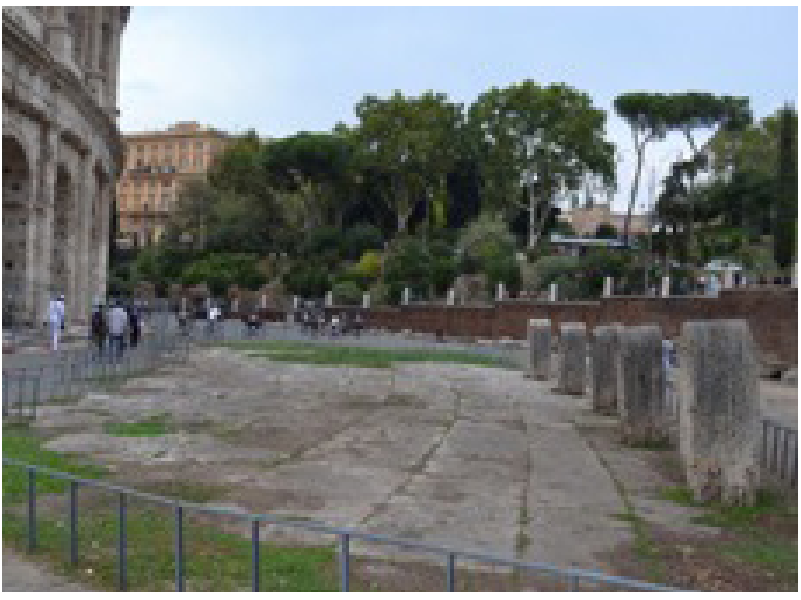

Figura 3. Termini del Coliseo, Roma. Foto: Angelo Coccaro.

pación de suelo perteneciente a un edificio público de espectáculo, por otro de sujeción de las cuerdas del velarium aprovechando que se encontraran ahí esas piedras, y por último el control peatonal de acceso al anfiteatro y vetar el acceso de los vehículos a esa zona (Figura 3). Igualmente ocurriría con las fuentes públicas en la ciudad romana de Pompeya, donde estas fuentes estaban rodeadas por termini, pero no solo tenían la función de delimitar el espacio público de las fuentes para no ser invadidas, sino que tenían una doble función, y es que posiblemente al mismo tiempo, servían como guardarruedas para que los carros al pasar no dañaran la estructura de la fuente (Figura 4). Por lo que, estos termini tenían su función principal de delimitación de espacios, pero eran aprovechados para otros usos ( $\mathrm{Ra}-$ poso, 2017).

\section{LA DELIMITACIÓN DE LOS ESPACIOS DE OCIO EN POM-} PEYA

En Pompeya contamos con una serie de edificios destinados al ocio. En Pompeya encontramos dos áreas destinadas al espacio de ocio para los ciudadanos. Por un lado, contamos con la zona $\mathrm{S}$ de la ciudad justo al lado del Foro Triangular, donde se encuentran el teatro, el odeón y la palestra Samnita (Figura 5). Por otro lado, en la zona SE de la ciudad encontramos la segunda zona destinada al ocio, en la que se sitúa el anfiteatro y la palestra Grande.

\section{TEATRO}

El teatro se encuentra situado en la insula VIII.7. 20-21, entre el Foro Triangular y el odeón (Figura 5). Se accede a él desde la "Via Stabiana" o desde el

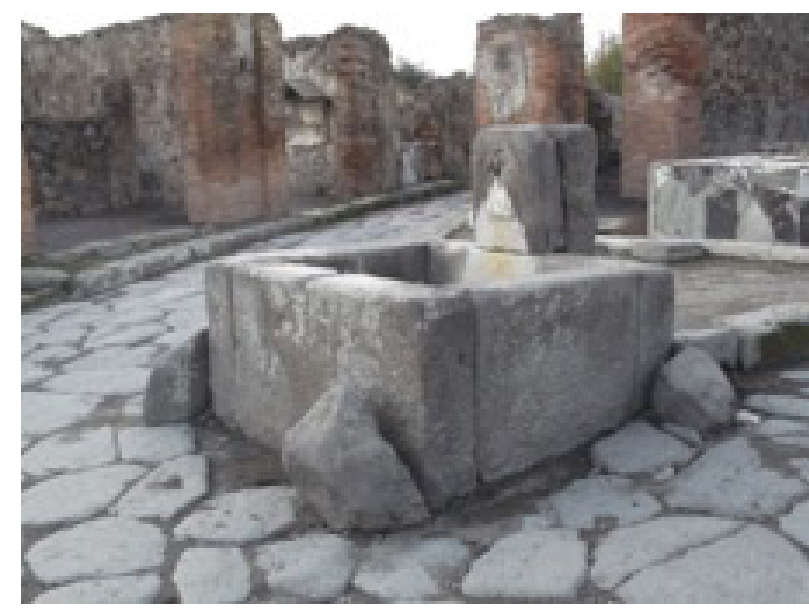

Figura 4. Fuente Via Consolare con Vico di Modesto. Pompeya. Foto: Noemí Raposo, 2016

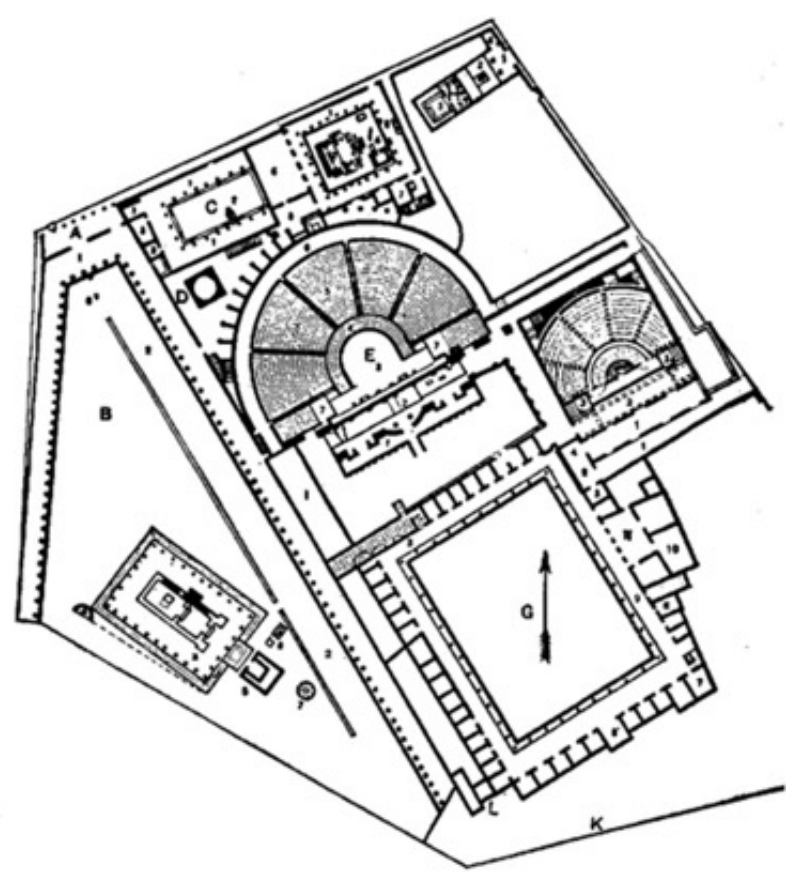

Figura 5. Plano del Foro Triangular, teatro, odeón y palestra samnita. Fuente: Etienne, 1971, 334

Foro Triangular a través de unas escaleras que dan acceso al pórtico del teatro (Figura 6 y 7 ).

Este teatro se construyó a principios del siglo II a.C. diseñado como un teatro griego y se amplió y reformó en época de Augusto para adaptarlo a la época romana, como podemos ver en algunas inscripciones situadas en el teatro (Thédenat, 1910, 78; Maiuri, 1950, 29 y Cooley y Cooley, 2004, 45), observamos como los magistrados Marcus Holconius Rufus y Marcus Holconius Celer, financia- 


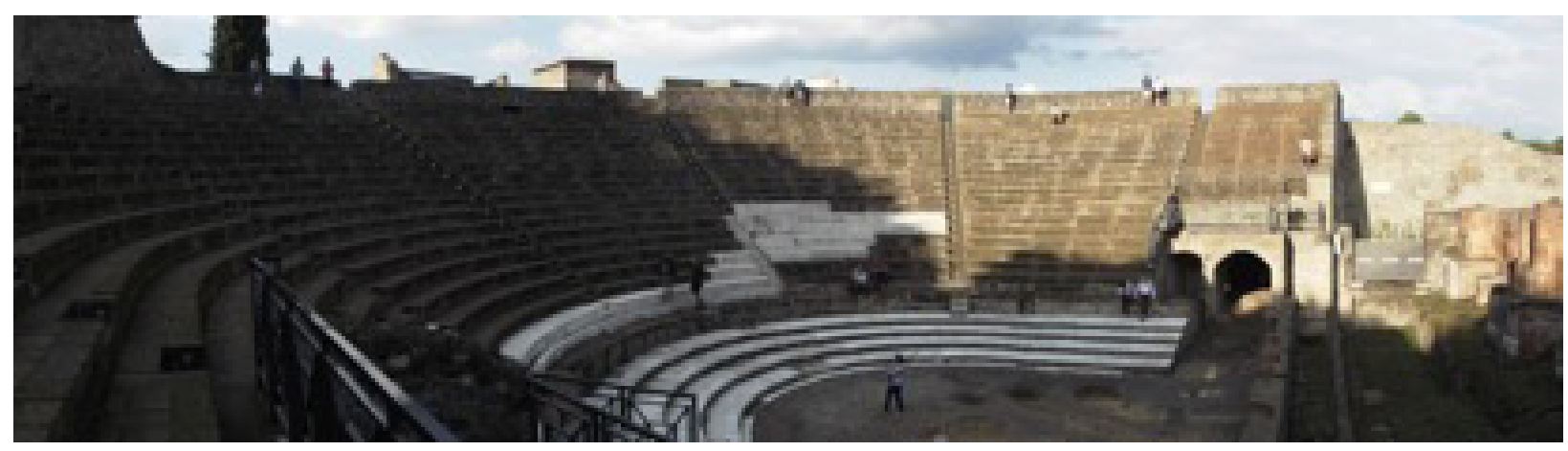

Figura 6. Teatro. Foto: Noemí Raposo, 2016

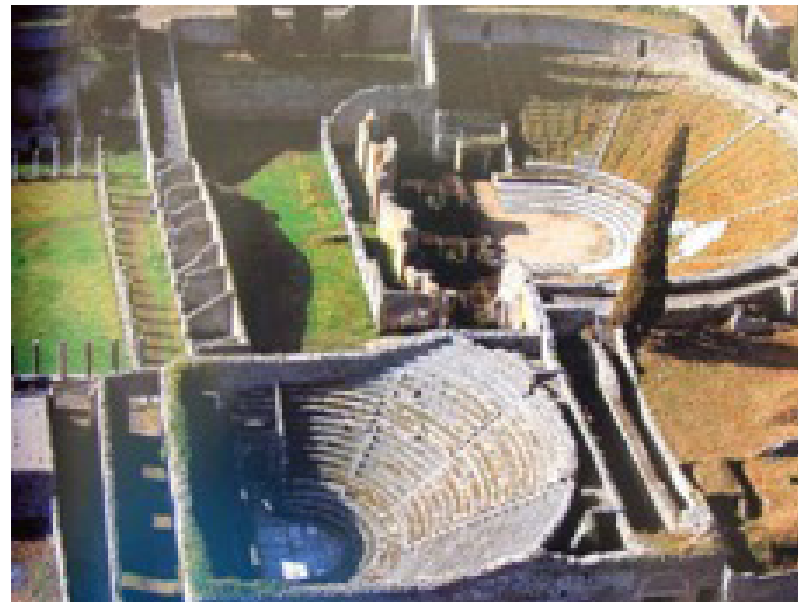

Figura 7. Odeón y teatro. Foto: J Mª Luzón Nogué

ron la restauración del pasaje cubierto que da acceso a la tribuna y a la cavea del teatro y contrataron al arquitecto Marcus Artorius para llevar a cabo tal obra (Vinci, 1839, 142; Fiorelli, 1977, 81-82; Mau, 1899, 144; Pellerano, 1910, 12; D’Amore, 1960, 52 y De Vos y De Vos, 1982, 64):

\section{M(arcus et) M(arcus) Holco[nii] Rufus et Celer [cryp]tam tribunalia theatrum s(ua) p(ecunia) $(\text { CIL X 834) })^{7}$. \\ M(arcus) Artorius $M$ (arci) l(ibertus) primus / architectus (CIL X 841) $)^{8}$.}

7 "Marco Holconio Rufo y Marco Holconio Celer, construyeron con sus propias expensas la cripta, la tribuna y el teatro" (CIL X 834).

8 "Marco Artorio Primo, liberto de Marco, arquitecto" (CIL X 841).
ODEÓN O TEATRO CUBIERTO

El odeón o teatro cubierto (theatrum tectum) se encuentra situado en la insula VIII.7.17-19, justo al lado del teatro y a él se accede desde la "Via Stabiana", aunque también se puede acceder desde el Foro Triangular por el pórtico del teatro hasta el odeón (Figura 7).

Este teatro cubierto u odeón fue construido durante los primeros años en los que Pompeya pasó a ser colonia romana. Los constructores fueron los duoviros Caius Quintius Valgus y Marcus Porcius, como podemos ver en una placa situada en la pared del teatro (Joiro, 1836, 89; Guarini; 1837, 31; Cesare, 1875, 78; Fiorelli, 1877, 80; Maiuri, 1950, 30; D’Amore, 1960, 54; Etienne, 1971, 337; Thédenat, 1910, 82; De Vos y De Vos, 1982, 70; Richardson, 1989, 133 y Parslow, 2007, 213-214):

C(aius) Quinctius C(ai) f(ilius)
Valg(us) / M(arcus) Porcius M(arci)
f(ilius) / duovir(i)dec(urionum) decr(eto)
/ theatrum tectum / fac(iundum)
locar(unt) eidemq(ue) prob(arunt) $($ CIL X
$844)^{9}$.

El odeón se encuentra situado dentro de un recinto rectangular y cubierto, que mide $28,60 \mathrm{~m}$ de ancho (96,50 pies) por $34,80 \mathrm{~m}$ de largo $(117,40$ pies) (Etienne, 1971, 337), por lo que se encuentra totalmente delimitado en su espacio y no sería posible invadirlo con ninguna construcción.

9 "Caio Quintio Valgo, hijo de Caio, Marco Porcio, hijo de Marco, duoviros por decreto de los decuriones, se le adjudicó el contrato para la construcción del teatro cubierto" (CIL X 844). 


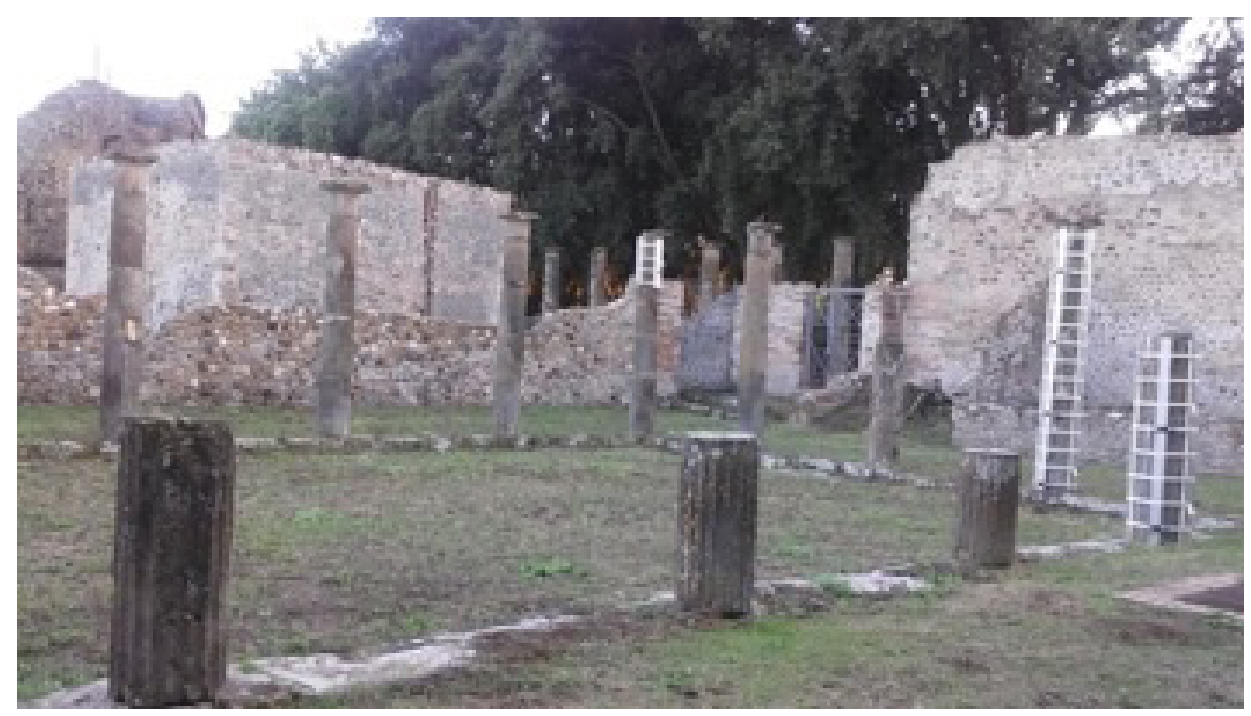

Figura 8. Palestra Samnita. Via del Tempio d’Iside. Foto: Noemí Raposo, 2016

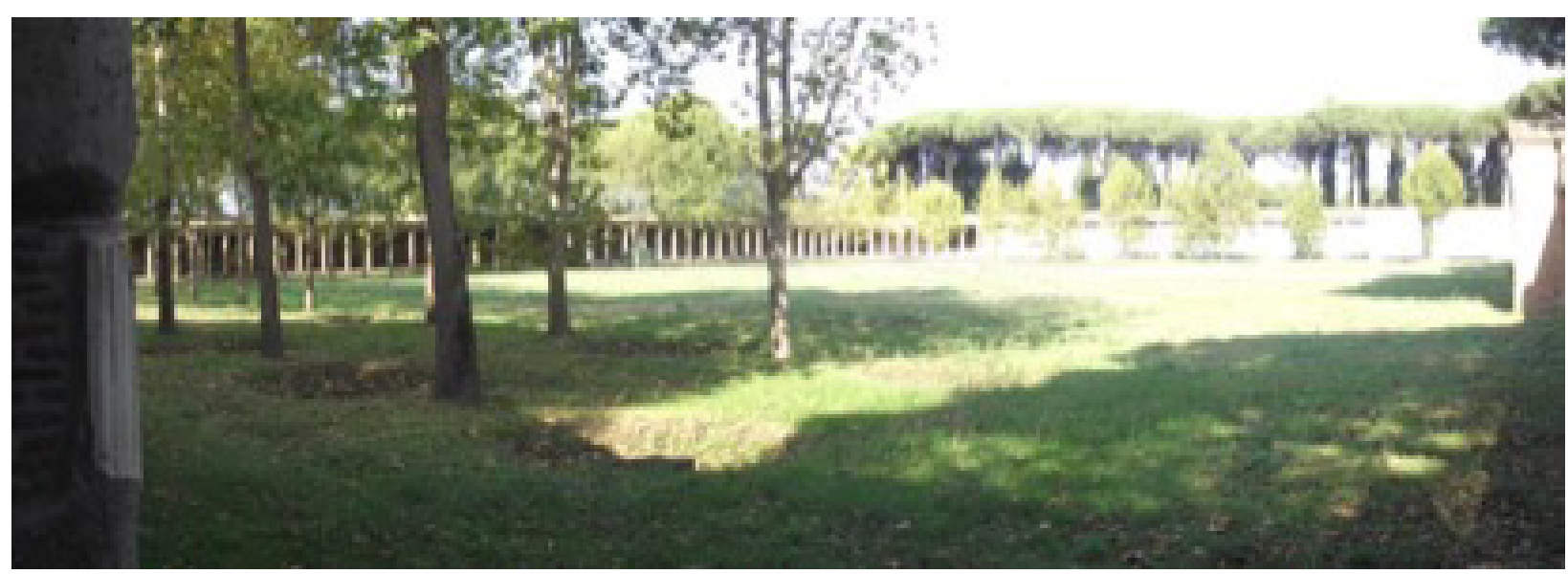

Figura 9. Palestra grande. Foto: Noemí Raposo, 2016

PALESTRA SAMNITA

La palestra Samnita se sitúa en la insula VIII.7.29 entre el Foro Triangular y el templo de Isis. Tiene dos accesos uno desde el Foro Triangular y otro desde la "Via del Tempio d'Iside" (Figura 8). Recibe este nombre porque su construcción se remonta a época prerromana, como podemos observar en la inscripción osca que en ella se localizó, en la que se testimonia que el cuestor Vibius Vinicius, con el dinero que Vibius Adiranus dejó en su testamento para la juventud pompeyana la construcción de este edificio (Mau, 1899, 159; Etienne, 1971, 349; De Vos y Vos, 1982, 71 y Mcdonald, 2012, 42):
V(iíbis) Aadirans V(iíbieís) eítiuvam paam / vereiiaí Púmpaiianaí tristaamentud / deded eisak eitiuvad / V(iibis) Viínikiís $M(a) r($ aheis) kvaísstur Púmpaiians tríbúm ekak kúmbennieis / tanginud úpsannam / deded ísídum prúfatted (De Vos y Vos, 1982, 71) ${ }^{10}$.

10 "Vibio Adiranus, hijo de Vibio, dio el dinero en su voluntad al pueblo de Pompeya. Con este dinero, Vibio Vinicio, hijo de Maras, cuestor de Pompeya, por decreto del senado emitió un contrato para la construcción de este edificio, y él mismo lo aprobó" (De Vos y Vos, 1982: 71). 


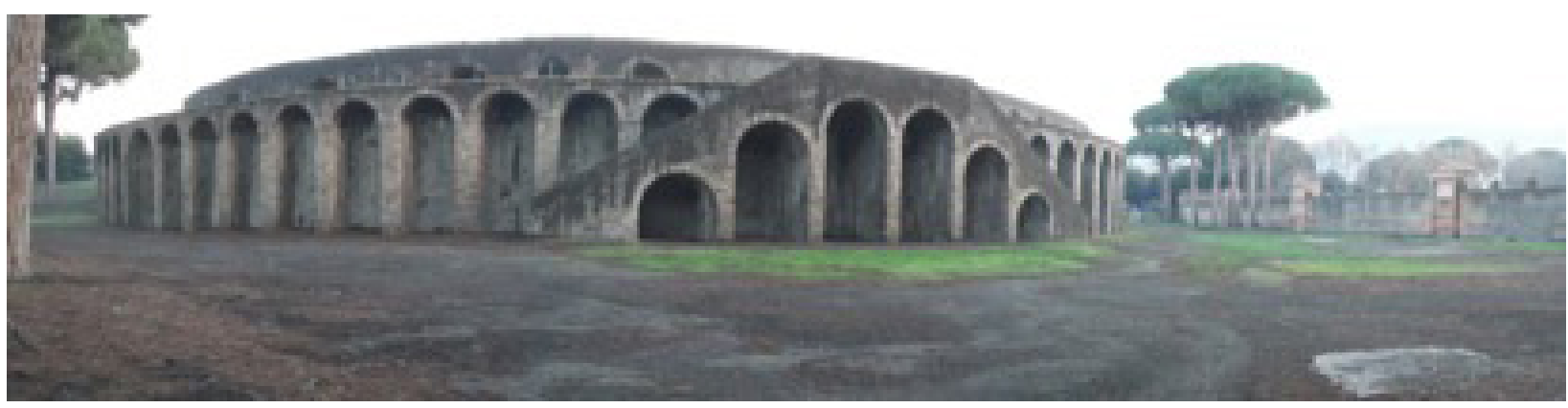

Figura 10. Anfiteatro. Foto: Noemí Raposo, 2014

Consiste en un patio porticado, con seis columnas en los lados largos y cinco en los pequeños, donde los ciudadanos iban a realizar sus ejercicios, pues se trata de un gimnasio al aire libre (Mau, 1899, 159; Sogliano, 1899, 19; Etienne, 1971, 348-349 y De Vos y Vos, 1982, 71). Al igual que el odeón se encuentra delimitada por un muro que la rodea que formaría el límite con otras propiedades.

\section{PALESTRA GRANDE}

La palestra grande situada en el extremo SE de la ciudad, en la insula II.7 junto al anfiteatro (Figura 9). Se encuentra delimitada al O por el anfiteatro, al $\mathrm{E}$ y $\mathrm{N}$ por las residencias con huertos y viñedos, $\mathrm{y}$ al el $\mathrm{S}$ por la muralla de la ciudad.

Recibe este nombre, porque es mucho más grande que la palestra Samnita. Esta palestra se construyó en época augustea y tiene unas dimensiones de unos $142 \mathrm{~m}$ de largo (479,15 pies) y unos $107 \mathrm{~m}$ de ancho (361 pies), lo que representa una superficie superior a la de seis insulae. Consiste en un espacio abierto porticado por tres de sus lados, quedando el lado $\mathrm{E}$ con un muro sin columnas y en el centro tiene una natatio (Figura 10) (Maiuri, 1959, 175-176; D'Amore, 1960, 57; Etienne, 1971, 350; Staccioli, 1982, 82 y De Vos y De Vos, 1982, 147). Cuenta con diez puertas de acceso, cinco desde la plaza del anfiteatro, tres desde el "Vico di Octavius Quartio" y dos al N por la "Via di Castricio" (Etienne, 1971, 350). Al igual que la palestra Samnita y el odeón las mismas paredes del edificio serían la delimitación del mismo.

\section{Anfiteatro}

El anfiteatro de Pompeya está situado en el extremo SE de la ciudad, concretamente en la insula II.6 (Figura 6). Este edifico no era denominado por los romanos como anfiteatro, sino con el término latino de spectacula, por lo que claramente era un edificio donde se llevaban a cabo una serie de espectáculos (Garrucci, 1853, 48; Mau, 1899, 206 y Ling, $2007,120)$. Se sitúa en un área dedicado exclusivamente a ser una zona de ocio donde se encuentra también la palestra Grande. El anfiteatro se delimita por la zona $S$ y E por la muralla de la ciudad, por la zona O por la palestra Grande y por la zona $\mathrm{N}$ por las casas y los viñedos situados en esa zona de la Regio II (Figura 10).

Se construyó en un área que equivale a seis insulae (Gesemann, 1996, 282) unos $15600 \mathrm{~m}^{2}$ (Spano, $1953,8)$. Tiene una forma elíptica, característica de los anfiteatros romanos, y sus medidas son $66,80 \mathrm{~m}$ de largo $(225,40$ pies $)$ y $35,40 \mathrm{~m}$ de ancho $(119,45$ pies) (Spano, 1953, 12). El anfiteatro pompeyano es uno de los edificios de este tipo más antiguos conservados del Imperio Romano, construido en el siglo I a.C. Su construcción se debe a los duoviros Caius Quintius Valgus y Marcus Porcius, los mismos constructores del odeón, que decidieron construir un anfiteatro con sus propios medios como agradecimiento a la ciudad por haber sido elegidos magistrados de Pompeya. Contamos con una inscripción en el anfiteatro que demuestra este hecho (Figura 11) (Bonucci, 1827, 195; Joiro, 1836, 112; Guarini, 1837, 32; Vinci, 1839, 149; Fiorelli, 1875, 69; Mau, 1899, 206; Sogliano, 1899, 26; Spano, 1953, 6; Curti, 1873, 115; Maiuri, 1950, 32; D’Amore, 1960, 54; Ciprotti, 1962, 52; De Vos y De Vos, 1982, 150-151; Thédenat, 1910, 94 y Pellerano, 1910, 3).

C(aius) Quintius C(ai)f(ilius) Valgus / M(arcus) Porcius M(arci)f(ilius) duo vir(i) quinq(uennales) coloniai honoris / caussa spectacula de sua / peq(unia) fac(iunda) coer(averunt) et coloneis / locum in perpetuom deder(unt) (CIL X 852) ${ }^{11}$.

11 "Caio Quinto Valgo, hijo de Caio, Marco Porcio, hijo 
Existe una limitada evidencia de que el anfiteatro se construyó en un área en la que existían casas de ciudadanos de clase media fechadas desde el siglo II a.C., pero que fueron destruidas para poder construir el anfiteatro en un lugar marginado de la ciudad, lejos de las casas y de los edificios públicos para poder tener controlada a la muchedumbre que acudía a los juegos y cerca de las puertas de la ciudad. Se piensa que la "Porta Nocera" y la "Porta Sarno" serían las más utilizada para acceder al anfiteatro por su cercanía al edificio (Campbell, 2015, 36).

Algo a destacar es que el anfiteatro por la zona $\mathrm{S}$ se apoya directamente en la muralla (Cooley y Cooley, 2004, 46). Esto era considerado una grave infracción según se recoge en la normativa urbana, ya que ningún elemento podía invadir o asentarse sobre la muralla porque eso ocasionaba que su uso quedara bloqueado: "No se permite hacer nada que perjudique o entorpezca el uso de las murallas de la ciudad" (Dig. 43, 6, 2) $)^{12}$. Sin embargo, el anfiteatro desde su construcción parece que se adosó a la muralla, por ello pensamos que al ser un edificio que se regulaba con una normativa interna, el constructor del edificio hubiera obtenido un permiso de los magistrados de la ciudad para poder adosarlo a la muralla.

Entre el anfiteatro y la palestra Grande existe un espacio que se identifica como una plaza decorada con árboles, donde los espectadores esperaban antes de los juegos para entrar al anfiteatro, además en ella y debajo de los arcos del anfiteatro, se establecían vendedores ambulantes. Podemos observar estas actividades comerciales en el famoso fresco sobre la lucha entre espectadores de Pompeya y de Nuceria en el anfiteatro encontrada en la "Casa di Anicetus" (I.3.23) (Figura 12).

Pensamos que estas actividades comerciales en la plaza del anfiteatro de Pompeya contaran con autorización de los ediles, ya que encontramos en los arcos exteriores del anfiteatro varios anuncios pintados que indican que fueron los ediles quienes autorizaron a los vendedores callejeros o a los buhoneros a desarrollar sus actividades bajo los arcos del edificio y los que les habían asignado sus puestos (Spano, 1953, 8; Maiuri, 1959, 191; Ciprotti, 1962,

de Marco, duoviros quinquenales, por el honor concedido, hicieron construir paera la colonia a sus propias expensas el edificio de espectáculo y se lo cedieron en perpetuidad a los ciudadanos de la colonia" (CIL X 852).

12 Dig. 43, 4, 2. In muris aliquid facere, ex quo damnum aut incommodum irrogetur, non permittitur.

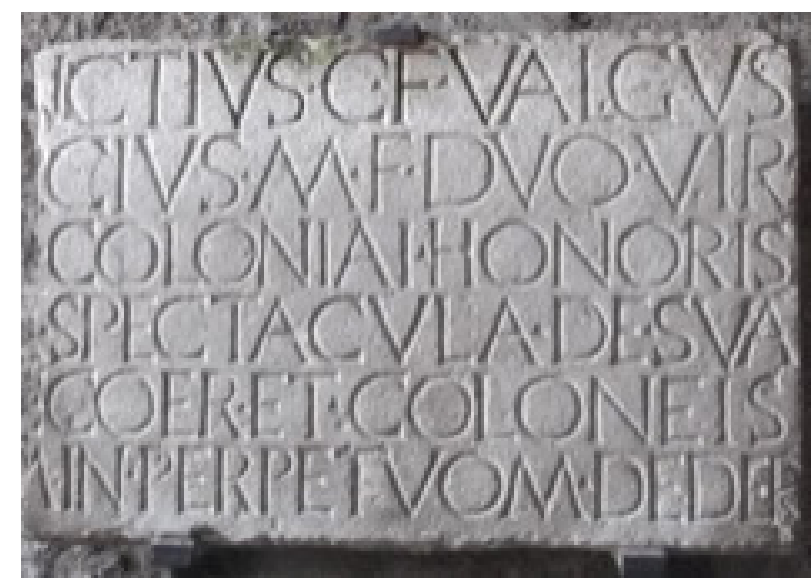

Figura 11. Inscripción de los constructores del anfiteatro. Anfiteatro. Foto: Noemí Raposo, 2016

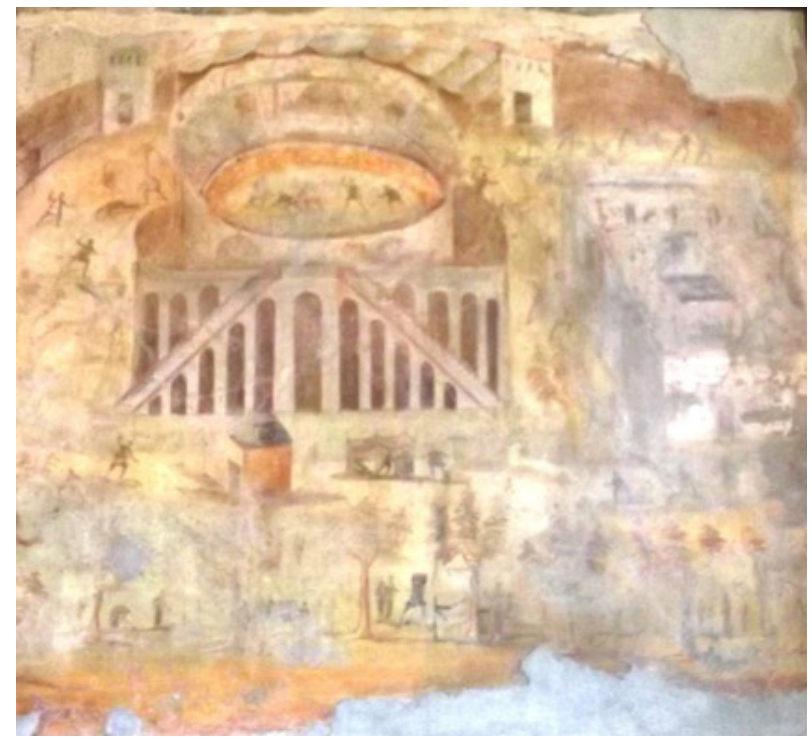

Figura 12. Lucha entre espectadores de Pompeya y Nuceria en el anfiteatro de Pompeya. Representación de comerciantes ambulantes. Museo Arqueológico Nacional de Nápoles. Foto: Noemí Raposo, 2016

54; Etienne, 1971, 184; Richardson, 1989, 135; Beard, 2009, 106; Berry, 2009, 142). Permissu aedilium Cn(aeus) Aninius Fortunatus occ(u)p(avit) (CIL IV 1096) ${ }^{13}$; [Per]missu aed[ilium] occupavit (CIL IV 1096a) ${ }^{14}$; Locu[s] occupatus est h[---] (CIL IV

13 "Gnaeus Anninius Fortunatus ha ocupado este lugar con autorización de los ediles” (CIL IV 1096).

14 "Con el permiso de los ediles para ocupar este lugar" (CIL IV 1096a). 
1097) ${ }^{15}$; Locu[s] oc[cup]atus est (CIL IV 1097a) ${ }^{16}$; [Per]missu aed[ilium] (CIL IV 1097b) ${ }^{17}$; Laelius Narcissus occupat (CIL IV 1115) ${ }^{18}$; [---]Ises hic (CIL IV 1129) $)^{19}$; Narcissus hic (CIL IV 1130) ${ }^{20}$; Permissu (CIL IV 2485) ${ }^{21}$; Permissum aedilium (CIL IV 2996)22; [Per]m[i]ssu oc[cu]pa[u]it (CIL IV 2996a $)^{23}$.

Además de ello pensamos que posiblemente la plaza del anfiteatro estuviera en su día rodeada por una serie de termini para delimitar tanto el espacio del anfiteatro como la plaza que posiblemente estuvieran unidos por la misma delimitación, ya que este espacio se configuró en su día probablemente para albergar la entrada y salida de los espectadores, como hemos visto con anterioridad en el Coliseo. Pero que en la actualidad no se encuentran como sucede en otras zonas de la ciudad de Pompeya, como por ejemplo el caso del "compitum d'Orfeo" cuyos termini fueron movidos de su sitio y amontonados en una esquina en el momento de la excavación, porque no sabían qué función tenían esas piedras rodeando la zona (Raposo, 2015, 110).

\section{CONCLUSIONES}

$\mathrm{Al}$ analizar los cinco edificios de ocio con los que cuenta la ciudad de Pompeya hemos comprobado que ninguno de ellos de delimita con termini como se recoge en la legislación urbanística relacionada con los espacios públicos. Sin embargo, estos edificios de ocio contaban con una normativa interna de la ciudad que los regulaba, algo que resulta difícil de encontrar, porque posiblemente, la normativa que regulaba su construcción se recogería en las leyes municipales de cada ciudad, pero no han llegado hasta nuestros días, y con mucha probabilidad serían diferentes unas de otras.

No obstante, pensamos que los edificios de ocio en Pompeya o bien han perdido los termini después de haber sido excavada la ciudad, ya que posiblemente no se sabía que esas piedras estuvieran delimitando una zona, o bien no se encuentran porque nunca existieron. La inexistencia entonces

\footnotetext{
15 "Este lugar está ocupado [---]" (CIL IV 1097).

16 "El lugar está ocupado" (CIL IV 1097a).

17 "Con el permiso de los ediles" (CIL IV 1097b).

18 "Laelius Narcissus ocupa este lugar" (CIL IV 1115).

19 "Aquí [ocupa su lugar] [---]ises" (CIL IV1129).

20 "Aquí [ocupa su lugar] Narciso" (CIL IV 1130).

21 "Con el permiso" (CIL IV 2485).

22 "Con el permiso de los ediles" (CIL IV 2996).

23 "Ha ocupado con el permiso" (CIL IV 2996a).
}

de esos termini puede ser debida a que los edificios como el odeón, la palestra Samnita y la palestra Grande estaban delimitados por unos muros, es decir el edificio se localizaba en el interior de un área muraría que los delimitaba, por lo tanto no era necesario demarcar la zona con termini, ya que era imposible que esos edificios fueran susceptibles de ser invadidos ni ellos invadir los espacios públicos. Por otro lado, con respecto al teatro es que no fuera necesario delimitarlo con termini, ya que se encontraba en un área delimitado en por todos sus lados imposible de ser invadido. Por último, lo que respecta al anfiteatro es muy probable que la plaza que lo rodea estuviera delimitada por termini que actualmente no se encuentran como sucede en el “compitum d'Orfeo", pero que en su día si estuviera delimitado y por la zona SE se encuentra delimitado por la muralla.

En conclusión, creemos que es razonable pensar que Pompeya optara por regular de una forma distinta la forma de delimitación de sus espacios de ocio, ya que no pensamos que se infringiera ninguna normativa al respecto, porque no se ha encontrado ninguna invasión a estos lugares ni de estos edificios hacia los espacios públicos, con excepción del anfiteatro hacia la muralla, pero al ser un edificio de ocio pagado por un magistrado tuviera permiso de los magistrados de la ciudad para adosarse a ella.

\section{Bibliografía}

Beard, M. (2009), Pompeya: historia y leyenda de una ciudad romana, Barcelona.

Berry, J. (2009), Pompeya, Madrid.

Bomgardner, D.L. (2000), The Story of the Roman Amphitheatre, Londrés, Nueva York.

Bonucci, C. (1827), Pompei descritta, Nápoles.

Campbell, V. (2015), The tombs of Pompeii: organization, space and society, Nueva York.

Cesare, F. (1845), Le più belle ruine di Pompei. Descritte, misurate e disegnate, Nápoles.

Ciprotti, P. (1962), Pompei, Roma.

Cooley, M. y Cooley, A. E. (2004), Pompeii. A sourcebook, Nueva York.

D’Amore, L. (1960), Pompei, Nápoles.

D’Ors, A. (1975), El digesto de Justiniano, vol. 1, Pamplona.

D’Ors, A. (1975), El digesto de Justiniano, vol. 3. Pamplona.

Daremberg, C. Saglio, E. y Pottier, E. (1877-1919), Dictionnaire des Antiquités Grecques et Ro- 
maines, d'après les textes et les monuments contenant l'explication des termes qui se rapportent auc moeurs, aux institutions, à la religión et en général à la vie publique et privée des anciens, tomo 5, vol. 1. París.

De Marco, N. (2004), I loci publici dal I al III secolo. Le identificazioni dottrinali, il ruolo dell'usus, gli strumenti di tutela, Nápoles.

De Vos, A. y De Vos, M. (1982), Pompei, Ercolano, Stabia. Guide Archeologiche di Laterza vol. 11. Laterza-Roma-Bari.

Etienne, R. (1971), La vida cotidiana en Pompe$y a$, Madrid.

Fiorelli, G. (1875), Descrizione di Pompei, Nápoles.

Fiorelli, G. (1877), Guida di Pompei, Roma.

García del Corral, I. (1889), Cuerpo del derecho civil romano. Digesto, vol. 1, Barcelona.

García del Corral, I. (1889), Cuerpo del derecho civil romano. Digesto, vol. 3, Barcelona.

García del Corral, I. (1889): Cuerpo del derecho civil romano. Instituta, vol. 4, Barcelona.

Geseman, B. (1996), Die Strassen der Antiken Stadt Pompeji: Entwicklung und Gestaltung, Berlín.

Guarini, R. (1837), Fasti Duumvirali di Pompei, Nápoles.

Hyginus y Siculus Flaccus (1998), Opuscula agrimensorum veterum vol. 1, (traducción y comentarios de Castillo Pascual, $\mathrm{M}^{\mathrm{a}} \mathrm{J}$.). Biblioteca de Textos Latinos, Logroño.

Joiro, A. (1836), Guida di Pompei, Nápoles.

Ling, R. (2007), "Development of Pompeii’s public landscape in the Roman period", The world of Pompeii (Foss, P.W. y Dobbins, J.J.), Nueva York, 119-128.

Lovato, A., Puliatti, S. y Solidoro Mauruotti, L. (2014), Diritto privato romano, Turín.

Maiuri, A. (1950), Pompeya. Las nuevas excavaciones. La Villa de los Misterios. El Antiquarium, Roma.

Maiuri, A. (1959), Pompei ed Ercolano fra case ed abitanti, Milán.

Mau, A. (1899), Pompeii. Its life and art, Londres.

Mcdonald, K. (2012), "The testament of Vibius Adiranus", Journal of Roman Studies 102, 40-55.

Mommsen, T. (1863), Corpus Inscriptionum Latinarum. Vol. X, pars 1, Inscriptiones Bruttiorum, Lucaniae, Campaniae, Siciliae, Sardiniae Latinae, Berlín.
Orlandi, S. (2004), Epifrafia anfiteatrale dell'Occidente romano: Roma. Anfiteatri e strutture annesse con una nuova edizione e commento delle iscrizioni del Colosseo, vol. 6, Roma.

Paolucci, F. (2006), Gladiatori. I dannati dello spettacolo, Roma.

Parslow, C. (2007), "Entertainment at Pompeii" (Foss, P.W. y Dobbins, J.J.), The world of Pompeii, Nueva York, 212-223.

Pellerano, B. (1910), Guida di Pompei: fatta sulle ultime innovazioni, Nápoles.

Raposo Gutiérrez, N. (2015), "Las aceras de Pompeya" (Calderón, M., España-Chamorro, S. y Montoya, R.), Estudios Arqueológico del Área Vesubiana I, BAR International Series 2701, 102-112.

Raposo Gutiérrez, N. (2017), La delimitación de los espacios públicos en Pompeya, Tesis doctoral inédita.

Richardson, L. (1989), Pompeii: an architectural history, Baltimore, Londres.

Sogliano, A. (1899), Guida di Pompei, Roma.

Spano, G. (1953), Alcune osservazioni nascenti da una descrizione dell'Anfiteatro di Pompei, Nápoles.

Staccioli, R. (1982), Pompei: vita pubblica di un'antica città, La Spezia.

Thédenat, H. (1910), Pompéi. Vie publique, París. Vinci, G. (1839), Descrizione delle ruine di Pompei, Nápoles. 
